\title{
Training on dispersed sites
}

\section{Discussion paper from the Education Committee}

\author{
Steffan Davies and John Cox
}

\begin{abstract}
The closure of large mental hosplitas, the move of services into the communily and the formation of mulliditrict rofictions have lod to a dispersed of trainees onto mony stles. This paper seeks to raise awcreness of the problems faced by treinees working and training on clupersed sties and sugoests some solutions. If is the product of discusedons within the Colleglate Trainees Commitive, the Education Committee and the Paychiaticic Tutors sub-committee.
\end{abstract}

Several factors have led to increasing dispersion of trainees from the hospital bases of the past. These include the formation of mult-district rotational training schemes, which have led to trainees being spread among hospitals in many different locations, often with centralised MRCPsych courses. The increase in the numbers of psychiatric sub-specialities on many schemes has also led to trainees, individually or in small numbers, moving to additional sites such as mental handicap hospitals and reglonal secure units. The move of services into the community leads to many juniors working on split sites with community teams, day hospitals, long-stay facllities and acute wards at different locations. More recently there have been proposals to replace old psychiatric hospitals with multiple small units, including admission beds, team bases and day hospital facilities scattered across health districts.

These changes have led to increased opportunities to train in different sub-specialties and in different environments, e.g. rural, inner-city, District General Hospital (DGH) units, large institutions and academic departments. The first authors' registrar rotation included five health authorities with adult acute admission beds on five sites, old age admission beds on two further sites, one Special Hospital, two mental handicap hospitals, an adolescent in-patient unit, day hospitals on five non-hospital sites and six hospital sites, and a large number of non-hospital team bases. There are also a wide variety of longer stay facilities in both hospital and community settings. Liaison services are also provided to six DGH's, some with on-site psychiatric services. There are 24 registrars on this rotation.
There are considerable difficulties caused by this wide variety and number of settings which are likely to be compounded by future developments, particularly of small dispersed admission units. These seem to fall in three main areas:

1. Problems with coordinating and attending educational activities.

2. Problems and consequences of covering multiple facilities during and out of working hours.

3. Personal and peer group consequences.

\section{Problems with coordinating and at- tending educational activities}

Multidistrict rotations usually have one centralised MRCPsych course which all pre-membership trainees are required to attend. This often leads to problems arranging daytime cover for units off the site of the teaching. This usually leads to either rotas being organised to cover between trainees, or General Practitioner Vocational Training Scheme trainees covering and attending their training courses on other days. This also leads to increased demands on those covering as they are often the only remaining junior doctor on a site which may normally have up to a dozen juniors. The large distances covered by rotations also make it difficult to attend educational activities for one session and return to the clinical area in time to perform a useful quantity of clinical work before returning home. If interview skills, research groups, psychotherapy training and supervision and exam preparation are to be provided, there needs to be a review of the central $v$. peripheral split in provision of these functions.

\section{Problems and consequences of cover- ing multiple facilities during and out of working hours}

Covering units on different sites often leads to multiple demands from acute wards, day units and overdose rotas, and being off site leads to greater delays for travelling and response time and reduces the time available for clinical tasks, 


\section{EDUCATION}

attending case conferences/journal clubs, and research. The use of multiple sites often leads to isolation from educational supervisors for prolonged periods and makes the maintenance of protected time for clinical and educational supervision more important and more difficult to achieve.

The need to provide 'duty doctor' cover to central acute wards, overdose duties, ECT, and casualty as well as covering for the MRCPsych course and off-site clinics, home visits or liaison visits often leads to multiple and complex rotas in addition to out of hours on-call. This can lead to a form of rota grid-lock making annual leave and study leave difficult to take, and can generate bad feeling. Out of hours cover also becomes complex with multiple community long-stay and admission wards without resident medical cover. The pressures of the 'New Deal', although welcome, lead to a reduction in the number of sites which can have a doctor resident.

The increased trend to dispersed acute admission units needs to be debated within the College. Should we produce a policy on acceptable standards of care, including medical cover for acute units? Is this an issue we should encourage the Department of Health and NHSE to address? Does the MHAC have a view - particularly for admission of detained patients? The Registrar proposes to set up a working group to address these and other issues.

\section{Personal and peer group consequences}

The move to more dispersed services also frequently leads to reduction of peer group support day to day. The transitory nature of junior doctors and their different responsibilities makes effective support from non-medical staff unlikely. There may also be a decrease in contact with educational supervisors which threatens the apprenticeship element of training. This also means a reduction in the number of central activities and meetings trainees can attend and leads to great problems coordinating activities between trainees such as research groups and peer groups. Results of this include personal and professional isolation and reduced cohesiveness among the rotation's trainees with particular problems for new trainees allocated to peripheral units.

\section{Recommendations}

Following debate within the Collegiate Trainees Committee, Education Committee and Psychiatric Tutors Sub-committee the following recommendations were made:

\section{Mandatory}

1. All rotations should provide secretarial support to the local junior doctors committees. Representatives from these committees should be members of the local division of psychiatry as well as the training committee.

2. There should be easily accessible facilities for formal and informal medical staff meetings such as a coffee room or mess.

3. All rotations should be able to show an accreditation visit that they have attempted to address the problems outlined above.

\section{Suggested solutions}

Every effort should be made to maintain local educational activities such as case conferences and journal clubs. This not only contributes to trainee education but also is accreditable activity for consultants under the College's Continuing Professional Development programme. These meetings also serve a social and organisational focus for individual sites. There should not be an expectation that centrally organised Membership courses provide all formal educational activities. Each site should have the use of a college tutor, who may be responsible for more than one site. While it may not be practical to have a College Tutor present on the smaller sites, there should be a designated Educational Supervisor with responsibility for each site, who should liaise closely with the appropriate College Tutor.

The balance of central and peripheral attachments, the size of rotations and travelling times within and between placements should be reviewed.

Sub-speciality experience - there should be formal educational activities within sub-speciality placements, these may be multi-disciplinary and/or may combine staff from several sites or districts.

Increased use of non-medical staff such as in DSH and liaison teams may reduce demands on juniors, reduce the number of duty rotas they are expected to participate in and help protect educational time.

Recommendations should be made on what it is reasonable to expect in terms of education, service standards and trainee support and supervision on dispersed sites.

New technology such as tele-conferencing may be of use in organising educational activities in widely dispersed schemes. There is however a need for trainees to meet regularly, face to face. and with opportunities for informal communication.

Personal tutor schemes - a designated tutor could keep in touch with trainees and help them gain familiarity with the rotation's organisation 
and provide a point of contact for any help they require. They may also provide longer-term support and career advice.

Mentor schemes - these should preferably be with an interested senior house officer or registrar.

Formal mechanisms should be set up to help trainees in difficulties, career or personal.

Review posts' timetables should be available to ensure adequate face to face contact, enabling proper clinical and educational supervision to take place. This needs to be direct consultant-junior contact and not included in multidisciplinary ward rounds or allocation meetings.

\section{Acknowledgements}

We would like to thank Dr. Boardman, Senior Lecturer, Community Psychiatry, University of Keele for comments on earlier drafts and Dr. M. Oates, Senior Lecturer, University of Nottingham for raising many of these issues at the College's Educational Forum.

Steffan Davies, Chairman CTC, Senior Registrar, Leicester Towers Hospital, and John Cox, Dean. The Royal College of Psychiatrists, London

Correspondence: Dr S. Davies, c/o Catherine Lightfoot, The Royal College of Psychiatrists, London 